OPEN ACCESS

Edited by:

Laura Rivino,

Duke-NUS Medical School, Singapore

Reviewed by:

Anuja Mathew,

University of Rhode Island,

United States

Anna-Lena Spetz,

Stockholm University, Sweden

${ }^{*}$ Correspondence: Annie Elong Ngono

aelong@lji.org

Sujan Shresta

sujan@lji.org

Specialty section:

This article was submitted to

Viral Immunology,

a section of the journal

Frontiers in Immunology

Received: 19 March 2019

Accepted: 23 May 2019

Published: 11 June 2019

Citation:

Elong Ngono A and Shresta S (2019)

Cross-Reactive T Cell Immunity to

Dengue and Zika Viruses: New

Insights Into Vaccine Development.

Front. Immunol. 10:1316

doi: 10.3389/fimmu.2019.01316

\section{Cross-Reactive T Cell Immunity to Dengue and Zika Viruses: New Insights Into Vaccine Development}

\author{
Annie Elong $\mathrm{Ngono}^{1 *}$ and Sujan Shresta ${ }^{1,2 *}$ \\ ${ }^{1}$ Division of Inflammation Biology, La Jolla Institute for Immunology, La Jolla, CA, United States, ${ }^{2}$ Department of Medicine, \\ School of Medicine, University of California San Diego, La Jolla, CA, United States
}

Dengue virus (DENV) is a member of the Flavivirus family that includes Zika virus (ZIKV), West Nile virus, Japanese encephalitis virus, and yellow fever virus. As the most prevalent of the flaviviruses, DENV is responsible for tens of millions of infections each year. The clinical manifestations of infection with one of the four DENV serotypes (DENV1-4) range from no symptoms to hemorrhagic fever and shock ("severe dengue"), which is fatal in $\sim 25,000$ patients annually. Many factors contribute to the development of severe dengue, including the DENV serotype and host expression of certain HLA alleles; however, it now seems clear that pre-existing immunity to DENV-and possibly other flaviviruses -is a major precipitating factor. While primary infection with one DENV serotype elicits strong cellular and humoral immune responses that likely confer long-lived protection against the same serotype, subsequent infection with a different serotype carries an increased risk of developing severe dengue. Thus, primary DENV infection elicits cross-reactive immunity that may be protective or pathogenic, depending on the context of the subsequent infection. Many flaviviruses share high sequence homology, raising the possibility that cross-reactive immunity to one virus may contribute to protection against or pathogenesis of a second virus in a similar manner. In addition, several flaviviruses are now endemic in overlapping geographic regions, underscoring the need to gain more knowledge about the mechanisms underlying cross-reactive immunity to different DENV serotypes and flaviviruses. Here, we review our current understanding of $\mathrm{T}$ cell immunity to DENV, focusing on cross-reactivity with other serotypes and flaviviruses such as ZIKV, and the role of DENV-elicited CD4 ${ }^{+}$and $\mathrm{CD}^{+} \mathrm{T}$ cells in protection. Recent work in this area supports a beneficial role for cross-reactive $T$ cells and provides new insights into the design of safe and efficient flavivirus/pan-flavivirus vaccines.

Keywords: cross-reactive T cell response, Dengue, Zika, Epitope Mapping, vaccine development

\section{INTRODUCTION}

Dengue virus (DENV) belongs to the flavivirus genus of the Flaviviridae family, which includes Zika virus (ZIKV), yellow fever virus (YFV), West Nile virus (WNV), and Japanese encephalitis (1). The flaviviruses are transmitted mainly through the bite of Aedes genus mosquitoes (namely, Aedes aegypti and Aedes albopictus), which have expanded to tropical and subtropical areas throughout 
the globe (2). DENV is currently endemic in more than 128 countries, most of which are developing nations where it imposes major public health and economic burdens. DENV exists as four serotypes (DENV1-4) that share $60-75 \%$ amino acid homology (3), and infection with any serotype can be asymptomatic or cause a spectrum of symptoms ranging from mild aches and pains to life-threatening dengue fever/hemorrhagic fever (DF/DHF) leading to shock; this syndrome is now referred to as "severe dengue." Approximately 100 million new symptomatic cases are reported annually, of which about $2 \%$ result in severe dengue, with 25,000 fatalities (4). This number is probably an underestimate considering the challenges in public health surveillance faced by many DENV-endemic countries. In the past few decades, the incidence of DENV has increased and expanded, and half of the global population ( $\sim 3.6$ billion people) is now estimated to be at risk for infection.

Efforts to understand why DENV infection causes such a range of symptoms have been ongoing for more than 60 years. Epidemiological studies showed that severe dengue was more prevalent in children and adults experiencing a secondary infection with a different DENV serotype (heterotypic) compared with the same serotype (homotypic infection) $(5,6)$. This and other observations suggested that DENV infection may elicit long-term protection against the same serotype but only shortterm protection or even enhanced infection with a different serotype. Although multiple factors, such as genetic variation, age, and sex contribute to the development of severe dengue (6), the mechanisms underlying the role played by the immune response in dictating whether DENV infection is protective or pathogenic are the dominant subject of continued research.

The research centers around two mutually non-exclusive hypotheses in which both humoral and cellular immunity to DENV contribute to disease pathogenesis. The first hypothesis stems from the process known as antibody $(\mathrm{Ab})$-dependent enhancement (ADE), whereby pre-existing cross-reactive Abs enhance the viral burden during subsequent heterotypic infection by promoting Fc $\gamma$ receptor-mediated cellular uptake. Increasing evidence from humans and mouse models support a direct role for DENV serotype-cross-reactive Abs in severe dengue (6-9). The second hypothesis for the enhanced disease risk during secondary DENV infection is built on studies suggesting a potential role for cross-reactive $\mathrm{T}$ cells in DENV pathogenesis $(10,11)$. According to the original $\mathrm{T}$ cell antigenic sin hypothesis, most activated $\mathrm{T}$ cells during acute DENV infection are crossreactive with a previously encountered serotype(s) and have low affinity for the currently infecting serotype, leading to suboptimal control of infection and disease pathogenesis (10). However, at present, the evidence is stronger for a protective rather than a pathogenic role for cross-reactive T cells in DENV infection (8). The relative contribution of host humoral $v s$. cellular immunity to the control of DENV infection is of great relevance for the development of safe and effective DENV vaccines. The only currently licensed DENV vaccine, Dengvaxia ${ }^{\circledR}$ (CYDTDV, Sanofi Pasteur), expresses the DENV E from YFV vector backbone which include the YF NS proteins and elicits $\mathrm{Ab}$ responses to DENV E protein (the major target of anti-flavivirus $\mathrm{Ab}$ responses) but not $\mathrm{T}$ cell responses to DENV NS proteins (the major targets of anti-DENV T cell response, as discussed below). Multiple clinical trials have revealed that Dengvaxia ${ }^{\circledR}$ elicits suboptimal $\mathrm{Ab}$ responses against all four DENV serotypes, and the vaccine-induced $\mathrm{Ab}$ responses wane within 3-4 years after vaccination $(12,13)$. In particular, analysis of pooled data from two phase 3 clinical trials of Dengvaxia ${ }^{\circledR}$ (CYD14 and CYD15) of Asian-Pacific and Latin American cohorts, respectively, revealed that young children ( $2-5$ years of age) who had not previously been exposed to DENV were at increased risk for developing severe dengue upon vaccination $(13,14)$. This was ascribed to unequal $\mathrm{Ab}$-mediated protection and low $\mathrm{T}$ cell responses elicited by the vaccine against the four DENV serotypes $(15,16)$, which may set the scene for $\mathrm{ADE}$ during subsequent infections. Thus, these Dengvaxia ${ }^{\circledR}$ findings support our hypothesis that the beneficial components of $\mathrm{T}$ cell responses should be harnessed in the design of optimal DENV vaccines (8).

A second flavivirus that has risen to the forefront of basic and clinical research in recent years is ZIKV. This virus was discovered in 1947 in Uganda, but the more recent outbreaks have brought worldwide attention to its potentially devastating effects, which include congenital ZIKV syndrome in infants born to ZIKV-infected mothers, and neurological disorders such as Guillain-Barre syndrome in adults (17). DENV and ZIKV share approximately $44 \%$ sequence identity at the amino acid level, are both widely distributed throughout the globe, and have overlapping areas of endemicity. These aspects, together with the studies of immunity to heterotypic DENV serotypes, raised the possibility that primary infection with DENV or ZIKV may induce an immune response cross-reactive with the reciprocal virus. Current work suggests that the mechanisms underlying cross-reactive humoral and cellular immunity resulting from ZIKV or DENV primary infection are as complex as those underlying heterotypic DENV infections (8). Here, we review recent developments in our understanding of the protective vs. pathogenic roles of DENV-elicited $\mathrm{T}$ cells in the context of subsequent infections with other DENV serotypes or ZIKV. The evidence presented here provides new insights into the need to consider both $\mathrm{Ab}$ and $\mathrm{T}$ cell immunity in the development of safe and effective flavivirus vaccines.

\section{IMMUNODOMINANCE OF DENV SEROTYPE-SPECIFIC T CELL RESPONSES IN HUMANS AND ANIMAL MODELS}

DENV is a positive-sense single-stranded RNA virus with an $\sim 11 \mathrm{~Kb}$ genome. As is the case for all flaviviruses, the DENV genome encodes three structural proteins (capsid [C], precursor membrane $[\mathrm{prM}]$, envelope $[\mathrm{E}]$ ) and seven nonstructural proteins (NS1, NS2A, NS2B, NS3, NS4A, NS4B, NS5). A comprehensive understanding of the immunodominant $\mathrm{T}$ cell epitopes in each flaviviral proteome, the parameters that influence their immunodominance, and the extent to which each epitope elicits $\mathrm{T}$ cell cross-reactivity to heterotypic serotypes/viruses, are of crucial importance for vaccine design.

Substantial effort using patient samples and mouse models has resulted in the identification of many $\mathrm{CD} 4^{+}$and $\mathrm{CD} 8^{+}$ 
$\mathrm{T}$ cell immunodominant epitopes during DENV and ZIKV primary and secondary infections. Some studies have taken the approach of testing isolated $\mathrm{T}$ cell responses to overlapping peptide libraries encompassing a viral protein or the entire viral proteome. Others have used predictive computational algorithms to identify the peptides most likely to interact with a given set of HLA or MHC molecules, which narrows the spectrum of epitopes to be screened. Studies using overlapping peptides spanning the DENV2 proteome identified NS3 as the most frequent target of the $\mathrm{T}$ cell response in DENV-infected patients in Thailand and India $(18,19)$. Using a similar approach with $\mathrm{T}$ cells isolated from DENV-infected Singaporean adults, Rivino et al. showed that $\mathrm{CD}^{+} \mathrm{T}$ cells targeted mostly NS3 and NS5 proteins, whereas the $\mathrm{CD} 4^{+} \mathrm{T}$ cell response was directed largely against C, E, and NS1 proteins (20). In contrast to the overlapping peptide approach, Weiskopf et al. used a $\mathrm{T}$ cell epitope prediction program to identify over 200 new $\mathrm{CD} 8^{+}$ $\mathrm{T}$ cell epitopes in DENV using peripheral blood mononuclear cells (PBMC) obtained from almost 200 healthy blood donors from Sri Lanka, and their results revealed that NS3, NS4B, and NS5 are the major $\mathrm{CD}^{+} \mathrm{T}$ cell targets (21). Using a similar comprehensive approach of identifying immunogenic epitopes with broad coverage of HLA types expressed worldwide, Weiskopf and colleagues demonstrated that NS3, NS5, and the structural protein $\mathrm{C}$ are the major target proteins of the antiDENV CD4 ${ }^{+} \mathrm{T}$ cell response in humans $(22-24)$. Collectively, these studies indicate that NS3 and NS5 are the major targets of the anti-DENV CD4 $4^{+}$and $\mathrm{CD}^{+}{ }^{+} \mathrm{T}$ cell responses in humans.

However, a challenge of examining $\mathrm{T}$ cell immunity in humans is that an accurate infection history is not always available. Non-Human Primates (NHP) do not develop severe dengue disease manifestations, including vascular leakage, and need high maintenance and cost for each study. The majority of mouse models are genetically modified to allow effective replication and development of clinical outcomes. Although, many of these mouse models lack one or more components of the IFN system, as DENV cannot inhibit the IFN signaling in mouse cells (unlike in human cells) to establish robust replication, they are still important as the first step to study protective/pathogenesis effects and test vaccine or antiviral drug candidates. In the context of investigating $\mathrm{T}$ cell responses, the antigenic load dictates the level of $\mathrm{T}$ cell responses to viruses (25), and thus WT mice, which do not support robust DENV replication, are not ideal for investigating the contribution of $\mathrm{T}$ cells in modulating viral replication and disease manifestations. Despite their limitations, these immunodeficient mouse models have therefore proven to be invaluable in identifying virus-specific and cross-reactive $\mathrm{T}$ cell epitopes. In particular, type I interferon (IFN) receptor (Ifnar1)-deficient mice, which are more susceptible than wildtype strains to DENV infection (26), backcrossed to HLA transgenic mice, which enable investigation of epitopes likely to be immunodominant in humans (27), have provided key insights into immunodominance patterns during primary and secondary DENV infections. Using a model of primary DENV2 infection in HLA-A*0201, $A^{*} 0101, A^{*} 1101, B^{*} 0702$, and DRB1*0101 transgenic Ifnar $1^{-/-}$mice, we first reported that the anti-DENV2 $\mathrm{CD} 8^{+} \mathrm{T}$ cells recognize predominantly NS3 and NS5 epitopes, and $\mathrm{CD}^{+}{ }^{+} \mathrm{T}$ cells recognize C, NS3, and NS5 epitopes (27). Moreover, the mice expressing known protective HLA molecules, such as HLA-B*0702, elicited broader and higher magnitude responses than an HLA associated with susceptibility to DENV infection (HLA-A*0101), in agreement with the human data (21). In contrast with DENV2, our model of primary DENV3 infection in HLA transgenic Ifnar $1^{-/-}$mice revealed that DENV3 induced a $\mathrm{T}$ cell response directed mainly (33\%) against $\mathrm{C}$, prM, and $\mathrm{E}$ epitopes, whereas only $3 \%$ of the $\mathrm{T}$ cell response in DENV2infected mice was against these proteins (28). Similar results were observed in humans, where the $\mathrm{CD} 8^{+} \mathrm{T}$ cell response in DENV3-infected individuals was directed more toward the structural proteins than the nonstructural proteins (29). We next modeled secondary homotypic and heterotypic DENV infections in HLA transgenic Ifnar $1^{-/-}$mice and observed that $\mathrm{CD} 8^{+}$ $\mathrm{T}$ cell responses were broad (targeting both structural and NS proteins) following primary and homotypic secondary infection, whereas $\mathrm{CD}^{+} \mathrm{T}$ cell responses following heterotypic secondary infection focused toward the conserved NS proteins (28), as observed in humans with natural DENV reinfections $(19,21$, 30). Collectively, the HLA transgenic mouse model and human data indicate that (i) the $\mathrm{CD}^{+} \mathrm{T}$ cell responses are mostly directed against nonstructural proteins NS3, NS4B, and NS5 for DENV1, 2, and 4 and both structural proteins (C, M, and E) and nonstructural proteins (NS3, NS4B, and NS5) for DENV3, (ii) $\mathrm{CD}^{+} \mathrm{T}$ cells preferentially recognize epitopes in C, NS3 and NS5 proteins, and (iii) primary infection is dominated by serotypespecific $\mathrm{T}$ cells, whereas memory $\mathrm{T}$ cells that recognize conserved epitopes are expanded together with naïve serotype-specific $\mathrm{T}$ cells during secondary infection (Figure 1). Thus, while epitopes from all DENV proteins can potentially be recognized by $\mathrm{CD} 4^{+}$ and $\mathrm{CD} 8^{+} \mathrm{T}$ cells, the precise pattern of immunodominance depends on the $\mathrm{T}$ cell type, the infecting serotype, and the individual's history of infection (Table 1).

\section{IMMUNODOMINANCE OF DENV-ELICITED ZIKV CROSS-REACTIVE T CELL RESPONSES}

Recent evidence indicate that DENV-elicited T cells are crossreactive also with ZIKV. Our study using a sequential model of DENV2 followed by ZIKV infection in Ifnar1 ${ }^{-/-}$HLA transgenic $B^{*} 0702$ and $A^{*} 0101$ mice showed that DENV2elicited $\mathrm{CD} 8^{+} \mathrm{T}$ cells recognized epitopes in ZIKV NS proteins, of which $\sim 40 \%$ were located in NS3 and $\sim 20 \%$ each in NS2A, NS4B, and NS5 (37). We also defined DENV2-elicited ZIKV cross-reactive epitopes in WT and congenic Ifnar1 ${ }^{-/}$mice in the C57BL/6 genetic background (38). We observed that DENV2-elicited CD8 ${ }^{+} \mathrm{T}$ cells mainly recognized epitopes in ZIKV NS3, NS5, prM and E, and that these cross-reactive $\mathrm{CD} 8 \mathrm{~T}$ cell responses dominated during ZIKV infection in Ifnar $1^{-/-}$and WT C57Bl/6 mice with Ifnar1 blockade (via pretreatment with blocking anti-Ifnarl $\mathrm{Ab}$ ). These mouse data have been validated by a human study that compared ZIKV cross-reactive $\mathrm{T}$ cells from naïve $v s$. DENV-exposed individuals from two DENV-endemic countries (Sri Lanka and Nicaragua) 


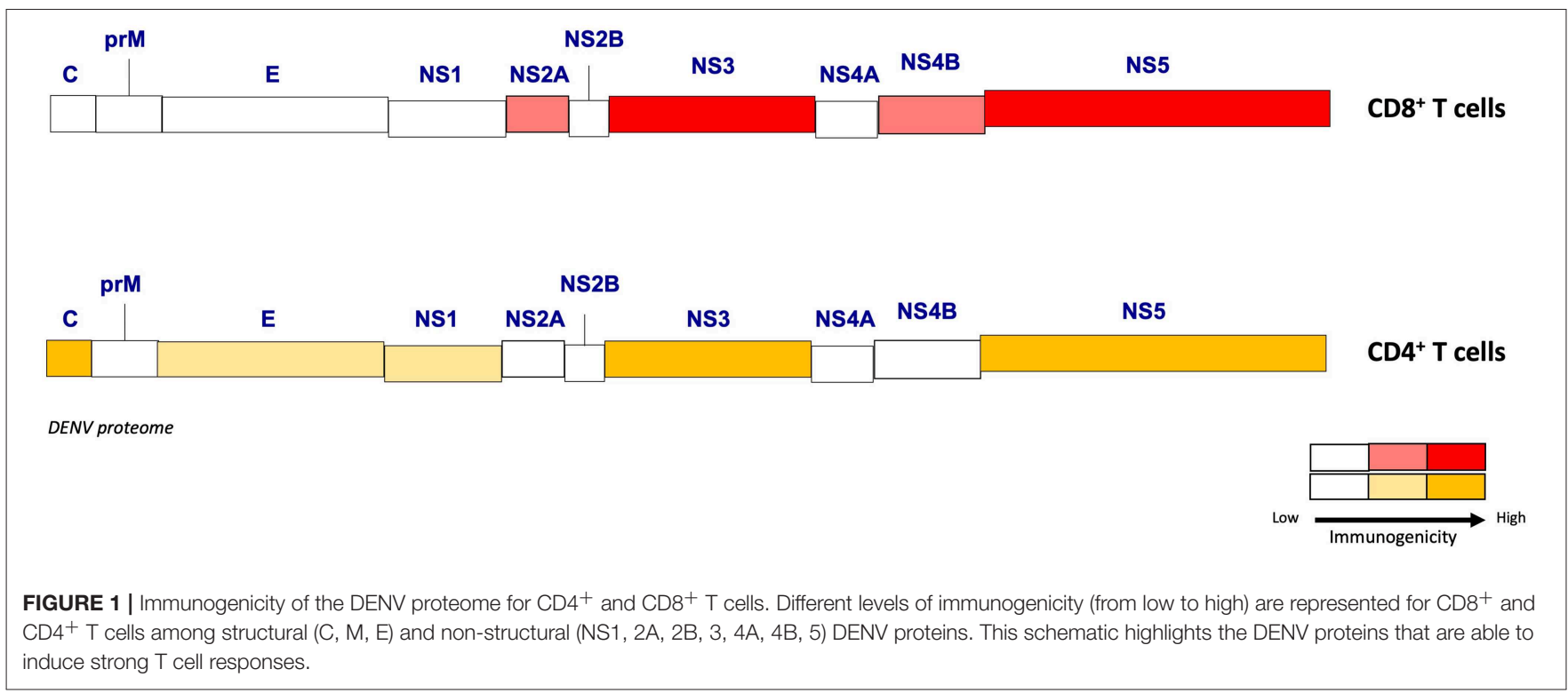

TABLE 1 | Parameters that influence the immunodominance of the T cell responses to DENV and ZIKV.

\begin{tabular}{|c|c|c|}
\hline Parameters & References & Conclusions \\
\hline Cell types & $(27,30)$ & $\begin{array}{l}\text { Distinct immunodominance patterns } \\
\text { between } \mathrm{CD}^{+} \text {and } \mathrm{CD}^{+} \mathrm{T} \text { cells }\end{array}$ \\
\hline Serotypes & $(23,28)$ & $\begin{array}{l}\text { DENV3 showed a distinct } \\
\text { immunodominance compared to } \\
\text { DENV1,2, } 4 \text { serotypes }\end{array}$ \\
\hline Sequence of infection & (28) & $\begin{array}{l}\text { The immunodominance patterns of T cells } \\
\text { are shaped by the serotype infecting } \\
\text { during the primary vs. secondary infection }\end{array}$ \\
\hline $\begin{array}{l}\text { Primary vs. secondary } \\
\text { infections }\end{array}$ & $\begin{array}{l}(21,28,31 \\
32)\end{array}$ & $\begin{array}{l}\text { During primary infection, serotype-specific } \\
\text { epitopes are targeted by CD4 }{ }^{+} \text {and } C D 8^{+} \\
\text {T cells, although conserved epitopes are } \\
\text { mostly targeted during secondary } \\
\text { infections }\end{array}$ \\
\hline HLA alleles & $\begin{array}{c}(21,23,27 \\
33-35)\end{array}$ & $\begin{array}{l}\text { Magnitude, frequency, and breadth of } \mathrm{T} \\
\text { cell responses are associated with } \\
\text { particular HLA alleles (protective or } \\
\text { susceptible HLA restriction) }\end{array}$ \\
\hline $\begin{array}{l}\text { Pre-existing immunity } \\
\text { to DENV }\end{array}$ & $(36-39)$ & $\begin{array}{l}\text { DENV-immunity modulated ZIKV } \\
\text { immunodominance patterns }\end{array}$ \\
\hline
\end{tabular}

(36). Specifically, Grifoni and colleagues observed not only that DENV-specific CD8 ${ }^{+} \mathrm{T}$ cells recognized ZIKV epitopes but also that prior exposure to DENV altered the pattern of epitope immunodominance (36). Thus, in vitro screening of $\mathrm{CD}^{+} \mathrm{T}$ cells from DENV-immune individuals showed a dominant response to epitopes in ZIKV non-structural proteins (mainly NS3 and NS5), whereas cells from DENV-naive individuals targeted C, $\mathrm{E}$, and prM. In line with this finding, a study with West African patients exposed to ZIKV and/or DENV showed that T cell cross-reactivity was more strongly directed against epitopes from the DENV and ZIKV NS3 helicase region (71\% sequence homology) than the protease region (53\% sequence homology)
(40). Similarly, in another study of DENV-immune individuals, several epitopes in ZIKV NS3 were recognized by cross-reactive DENV-elicited $\mathrm{CD}^{+}{ }^{+}$and $\mathrm{CD}^{+}{ }^{+} \mathrm{T}$ cells, whereas fewer crossreactive epitopes were located in ZIKV C protein (41). The high level of sequence conservation among flaviviral NS3 proteins most likely explains the immunodominant response to NS3. Collectively, these mouse and human studies have demonstrated that DENV-elicited $\mathrm{CD}^{+}$and $\mathrm{CD}^{+}{ }^{+} \mathrm{T}$ cells are highly crossreactive with ZIKV. Additionally, in the context of reciprocal infection, mouse studies have already shown that ZIKV-elicited $\mathrm{CD}^{+} \mathrm{T}$ cells are cross-reactive with DENV. Further studies with animal models and humans in particular are now necessary to define the precise features of the cross-reactive ZIKV-elicited T cells against DENV and vice-versa.

\section{PATHOGENIC VS. PROTECTIVE FUNCTIONS OF DENV-ELICITED CROSS-REACTIVE T CELLS}

Earlier studies with DENV-infected humans suggested that $\mathrm{T}$ cells may be playing a pathogenic role during secondary infection with heterotypic DENV. In particular, Green et al. reported that activated T cells $\left(\mathrm{CD}^{\circ} 9^{+}\right)$were more abundant in patients with severe dengue compared with mild disease or no symptoms (42). In addition, Mongkolsapaya et al. observed a higher frequency of DENV-reactive $\mathrm{CD}^{+} \mathrm{T}$ cells with low affinity in patients experiencing severe dengue compared with mild disease (10). These results were in agreement with other studies demonstrating different immune profiles (cytokine production and cytotoxicity) for $\mathrm{CD}^{+}$and $\mathrm{CD}^{+} \mathrm{T}$ cells from severe dengue patients compared with mild dengue patients $(19,43)$. For instance, NS3-specific $\mathrm{CD}^{+} \mathrm{T}$ cells from donors with severe dengue had a higher production of tumor necrosis factor (TNF) vs. IFN $\gamma$ compared with children with mild dengue (19). Along the same line, $\mathrm{CD}^{+} \mathrm{T}$ cells from Thai school 
children with secondary DENV infection produced more TNF when stimulated with heterotypic DENV antigens compared with homotypic antigens in vitro (43). In support of these human studies implicating a pathogenic role for cross-reactive $\mathrm{T}$ cells during DENV infections, a study with wildtype C57BL/6 mice demonstrated that adoptive transfer of DENV1-elicited CD8 ${ }^{+} \mathrm{T}$ cells into naïve mice triggered some signs of disease following DENV2 challenge (44). However, wildtype C57BL/6 mice are highly resistant to DENV infection, do not develop vascular leakage, a hallmark of severe dengue, and the $\mathrm{T}$ cell response in wildtype mice may be limited due to a small antigenic load (8). Thus, at present, direct evidence linking cross-reactive $\mathrm{T}$ cells to severe dengue pathogenesis is lacking.

On the other side of the protective $v s$. pathogenic immunity debate, increasing evidence supports a protective role for DENV serotype-cross-reactive $\mathrm{CD}^{+}{ }^{+}$and $\mathrm{CD} 8^{+} \mathrm{T}$ cells. In particular, comprehensive epitope identification studies have revealed that $\mathrm{CD}^{+}$and $\mathrm{CD} 8^{+} \mathrm{T}$ cell responses restricted to HLA molecules associated with a "low risk" of severe dengue display more robust and polyfunctional responses than cells restricted to "highsusceptibility" HLA molecules $(21,23)$. Weiskopf et al. used healthy blood donors from a DENV hyperendemic country, Sri Lanka, with $80 \%$ of the general population being DENV seropositive. Detailed analysis of DENV epitope-specific CD8 ${ }^{+}$ $\mathrm{T}$ cell responses in healthy DENV-immune individuals showed no differences in the magnitude, phenotype, functionality, and avidity of the responses to serotype-specific and conserved epitopes (21). Notably, the magnitude, frequency, and breadth of the memory $\mathrm{T}$ cell responses were dictated by the restricting HLA, in that presentation by protective HLA molecules $\left(B^{*} 3501, B^{*} 0702\right.$, and $\left.B^{*} 5801\right)$ elicited strong and broad responses compared with susceptible molecules (HLA-A*2402 and $\left.\mathrm{A}^{*} 0101\right)$ (21). Consistent with these findings, examination of the transcriptional signatures of PBMC from asymptomatic and symptomatic DENV-infected individuals revealed higher expression of genes related to adaptive immunity and $\mathrm{T}$ cell activation in the asymptomatic subjects compared with the patients with severe dengue (45). More recently, a higher frequency of DENV-specific $\mathrm{T}$ cells was detected in patients with mild dengue relative to those with severe dengue (46). Collectively, these human data implicate a protective role of $\mathrm{T}$ cells in dengue disease control. However, more studies evaluating the precise phenotype and epitope specificity of $\mathrm{CD} 4^{+}$and $\mathrm{CD} 8^{+}$ $\mathrm{T}$ cells during various phases of DENV infection (acute and convalescence) are needed to better understand the contribution of $\mathrm{T}$ cells in protective vs. pathogenic immunity.

In line with the human data, studies using models of DENV infection in gene-deficient mice lacking type I IFN receptor or both type I and II IFN receptors, which can support robust DENV replication and manifest severe dengue-like disease, have provided direct evidence in support of a protective role for serotype-cross-reactive T cells (47-49). Higher mortality and viral tissue burden were observed in mice that had been primed with DENV4, depleted of $\mathrm{CD}^{+} \mathrm{T}$ cells, and then challenged with DENV2 compared with similarly treated $\mathrm{CD}^{+} \mathrm{T}$ cellsufficient mice (48). Transfer of DENV4-elicited CD8 ${ }^{+} \mathrm{T}$ cells to naive mice reduced the viral burden upon challenge with
DENV2, whereas $\mathrm{CD} 8^{+} \mathrm{T}$ cells were not required for protection after challenge with homotypic DENV4 (48). Moreover, DENV2cross-reactive $\mathrm{CD}^{+} \mathrm{T}$ cells contributed to the control of viral burden in HLA-B* 07 transgenic mice after vaccination with variant peptides from other DENV serotypes (49). Taken together, the human and mouse data indicate that serotype-crossreactive $\mathrm{CD} 8^{+} \mathrm{T}$ cells are important mediators of protection against DENV infection.

Recent human studies have also begun to identify potential $\mathrm{T}$ cell-based correlates of protection against DENV in the context of both natural infections $(21,50,51)$ and vaccination (TV003/TV005) $(24,50)$. A protective $\mathrm{CD}^{+} \mathrm{T}$ cell response appears to be driven by DENV-specific effector memory $\mathrm{T}_{\mathrm{EM}}$ $\left(\mathrm{CCR}^{-}{ }^{-} \mathrm{CD} 4 \mathrm{RA}^{-}\right)$and $\mathrm{T}_{\mathrm{EM}}$ expressing CD45RA, known as $\mathrm{T}_{\text {EMRA }}\left(\mathrm{CCR}^{-} \mathrm{CD}^{-} \mathrm{CRA}^{+}\right.$). Both $\mathrm{CD}^{+} \mathrm{T}_{\mathrm{EM}}$ and $\mathrm{T}_{\mathrm{EMRA}}$ subsets produce IFN $\gamma$ and TNF, express cytotoxic molecules such as granzyme B or CD107a, and upregulate PD1. A positive correlation between the expression of PD-1 and the magnitude of the $\mathrm{CD} 8^{+} \mathrm{T}$ cell response restricted by HLA* $\mathrm{B} 3501$, associated with a low risk of developing severe dengue, has been observed (51). $\mathrm{CD} 8^{+} \mathrm{T}_{\mathrm{EM}} / \mathrm{T}_{\mathrm{EMRA}}$ cells in blood from dengue-infected adults during acute phase (52) expressed high levels of CLA (cutaneous lymphocyte-associated antigen), a skin homing receptor, and chemokine receptors CXCR3, CCR5, and CXCR6, which support $\mathrm{T}$ cell migration to inflamed tissues (52). In this study, CLA-expressing DENV-specific $\mathrm{CD}^{+}$and $\mathrm{CD} 4^{+} \mathrm{T}$ cells were able to home to the skin during acute DENV infection, suggesting that these cells may be retained in the skin as first line of defense during DENV reinfection. Taken together, these observations indicate that the phenotypes of DENV-specific $\mathrm{CD}^{+} \mathrm{T}$ cells that are associated with protection include $\mathrm{T}_{\mathrm{EM}}$ and $\mathrm{T}_{\text {EMRA }}$ subsets expressing IFN $\gamma$, TNF, cytotoxicity markers, PD1, CLA, and chemokine receptors CXCR3, CCR5, and CXCR6, and they suggest that the anti-DENV CD8 ${ }^{+} \mathrm{T}$ cells may exert antiviral effects both through production of cytokines such as IFN $\gamma$ and TNF and cytotoxicity.

The phenotype of DENV-specific $\mathrm{CD}^{+} \mathrm{T}$ cells that are associated with protection have also begun to be investigated. In a study involving healthy donors, a higher frequency of DENV-specific CD4 ${ }^{+} \mathrm{T}_{\text {EMRA }}$ that produce more IFN $\gamma$ than $\mathrm{CD}^{+} \mathrm{T}_{\mathrm{EM}}$ or $\mathrm{T}_{\mathrm{CM}}$ cells and express CXCR3 and cytolytic molecules (e.g., granzyme B and perforin) was found in the blood of individuals classified as primary or secondary infections compared with dengue-negative healthy individuals (53). There was no significant difference between primary vs. secondary infection groups. In this study, secondary infection referred to seropositive healthy donors with neutralizing titers to more than one serotype and primary infection corresponds to donors with neutralizing titers to only one serotype. These IFN $\gamma$-producing cytotoxic $\mathrm{CD}^{+} \mathrm{T}$ cells (CTL) were more abundant in donors expressing HLA associated with protection (HLA DRB1*0401) than those associated with susceptibility to DENV infection (HLA DRB1*0802) (53). Recently, single-cell RNA sequencing identified DENV-specific CD4 ${ }^{+}$T CTL as a distinct population (54). In addition to $\mathrm{CD} 4^{+} \mathrm{CTLS}, \mathrm{CD} 4^{+}$follicular $\mathrm{T}$ helper cells (Tfh) that express $\mathrm{CXCR} 5^{+}$have been observed in PBMCs from convalescent DENV-infected patients after stimulation with 
DENV peptides (30). A recent study of DENV-infected children in Thailand showed that peripheral Th cells were expanded and activated (PD- $\left.1^{\text {hi }}, \mathrm{CD} 38^{+}\right)$during acute infection, and a higher frequency of activated Tfh cells were observed in patients with severe disease relative to those with mild disease (55). Thus, the magnitude and precise phenotype of $\mathrm{CD} 4^{+} \mathrm{T}$ cells that are polarized to cytotoxic Th1 and Tfh cells may serve as important correlates of protection against DENV infections.

Since the recent emergence of ZIKV in the Americas, studies have begun to examine how prior infection with DENV influences T cell immunity and the pathogenesis of ZIKV. Similar to the observations in patients with heterotypic DENV secondary infection, $\mathrm{CD}^{+}$and $\mathrm{CD} 8^{+} \mathrm{T}$ cells from $\mathrm{DENV}$-immune humans (naturally infected or vaccinated) are mostly $\mathrm{T}_{\mathrm{EM}} / \mathrm{T}_{\mathrm{EMRA}}$, express more polyfunctional cytokines, and display higher levels of cytotoxicity and activation markers (granzyme B, PD-1) than cells from ZIKV-infected DENV-naïve individuals $(36,40,56)$. Importantly, studies modeling sequential DENV followed by ZIKV infection in a variety of mouse strains, including Ifnar $1^{-/-}$ HLA transgenic, wildtype, and Ifnar $1^{-/-}$, have demonstrated that DENV-elicited $\mathrm{CD}^{+} \mathrm{T}$ cells are required for protection against ZIKV infection in both non-pregnant and pregnant mice $(37-39,57)$. Thus, these mouse model studies suggest that prior DENV immunity can afford cross-protection against ZIKV via $\mathrm{CD}^{+} \mathrm{T}$ cells.

Altogether, evidence to date supports an important role for DENV-elicited $\mathrm{CD}^{+} \mathrm{T}$ cells in mediating protection against heterotypic DENV and ZIKV infections. In comparison with $\mathrm{CD} 8^{+} \mathrm{T}$ cells, the function of cross-reactive $\mathrm{CD} 4^{+} \mathrm{T}$ cells during sequential infection with heterotypic DENV serotypes or with DENV and ZIKV has been explored to a lesser extent. Mouse models are thus poised to reveal the precise roles of the crossreactive $\mathrm{CD} 4^{+} \mathrm{T}$ cell responses and the interplay between the pre-existing DENV-elicited $\mathrm{CD}^{+}$and $\mathrm{CD}^{+}{ }^{-} \mathrm{T}$ cell responses during various reinfection settings.

\section{DESIGNING ANTI-FLAVIVIRAL VACCINES TO INDUCE BOTH T CELL AND HUMORAL IMMUNITY}

The quest for a safe and effective DENV vaccine has been ongoing for nearly 70 years. However, one of the most successful human vaccines designed to date is the live-attenuated yellow fever virus vaccine (YFV-17D), which has significantly reduced the incidence of this important flaviviral disease worldwide. YFV-17D induces strong $\mathrm{Ab}$ and $\mathrm{T}$ cell responses that mediate long-term protection in humans (58), and the YFV-17D-elicited $\mathrm{CD}^{+} \mathrm{T}$ cell response includes terminally differentiated $\mathrm{CD} 8^{+}$ $\mathrm{T}_{\mathrm{EMRA}}$ cells that express PD-1 and are highly proliferative and polyfunctional (59). To produce Dengvaxia ${ }^{\circledR}$, Sanofi Pasteur generated chimeric viruses with $\mathrm{prM}$ and $\mathrm{E}$ proteins from DENV1-4 and NS proteins from YFV-17D. This is currently the only licensed DENV vaccine and it has several drawbacks. The vaccine elicits suboptimal $\mathrm{Ab}$ responses with differential neutralizing activity against the four DENV serotypes; for example, titers of anti-DENV2 neutralizing Ab are particularly low (15), which could explain the elevated risk of severe dengue observed in vaccinated 2- to 5-year-olds (14). In addition, Dengvaxia ${ }^{\circledR}$ failed to protect naïve individuals $(14,60)$. Based on these outcomes, Dengvaxia ${ }^{\circledR}$ is recommended only for DENV-immune individuals older than 9 years of age (13). The failure of Dengvaxia ${ }^{\circledR}$ to fully protect may well be due to the absence of DENV NS proteins, which, as noted here, are the predominant targets of DENV-specific and cross-reactive $\mathrm{T}$ cell responses. In contrast, the vaccine's beneficial effect in DENVimmune individuals could result from a combination of the $\mathrm{Ab}$ response and stimulation of pre-existing DENV-elicited, YFV NS3-cross-reactive T cells (61). This possibility is supported by studies showing that Dengvaxia ${ }^{\circledR}$ induced a strong antiYFV NS3 $\mathrm{CD}^{+} \mathrm{T}$ cell response in DENV-naïve individuals but a weak anti-DENV $\mathrm{CD}^{+} \mathrm{T}$ cell response in DENV-immune individuals $(16,62)$. This observation substantiates the need to include immunodominant DENV-specific proteins in vaccines against DENV.

Two different DENV vaccine candidates (from Takeda and NIH/Butantan) that also represent live-attenuated chimeric viruses are now in phase III trials and have shown promising results in eliciting both cellular and humoral immune responses. TV003 is a tetravalent formulation composed of DENV1-3 and a chimeric DENV2 that includes prM and E from DENV2 and other proteins from DENV4. A single dose of TV003 has been shown to induce neutralizing Abs in up to $90 \%$ of vaccinees (63) and polyfunctional $\mathrm{T}$ cell responses that mainly target the most conserved epitopes in NS3 and NS5 (50). Another liveattenuated DENV vaccine candidate, TAK-003 from Takeda, is a tetravalent formulation of DENV2 and prM and E from DENV1, DENV3, and DENV3 within the same DENV2 backbone. This vaccine candidate induces a polyfunctional $\mathrm{CD}^{+} \mathrm{T}$ cell response against DENV2 NS1, NS3, and NS5 proteins that is crossreactive on the same proteins from DENV1, 3, and 4 (64). However, the absence of nonstructural proteins from DENV1, 3 , or 4 in this vaccine may be limiting, given that the pattern of immunodominant epitopes is influenced not only by the serotype but also by the vaccinee's infection history (28). In addition, it is important to note that the cross-reactive $\mathrm{T}$ cell response to heterologous flaviviral infection confers only shortterm protection (39). Long-term monitoring of the vaccinated individuals is necessary to determine whether vaccines can induce a sustained cross-reactive $\mathrm{T}$ cell response, which is the ideal outcome.

Several ZIKV vaccine candidates have been tested in animal models (65). Of these, prM/E DNA vaccines have shown the most promising results, but they appear to elicit poor $\mathrm{T}$ cell responses, despite high neutralizing anti-E protein Ab titers, in both mice (66) and rhesus monkeys (67). Moreover, the monkey study demonstrated protection against ZIKV infection that correlated with the $\mathrm{Ab}$ titer, but transfer of $\mathrm{Abs}$ from vaccinated to naïve monkeys conferred only partial protection against subsequent $\mathrm{ZIKV}$ infection (67), suggesting that $\mathrm{Ab}$ responses alone may be insufficient for full protection. Importantly, ZIKV-elicited Abs are able to induce ADE of DENV infection in vitro and in vivo (68-70). This finding underscores the potential dangers of vaccinating DENV-immune individuals with a ZIKV 

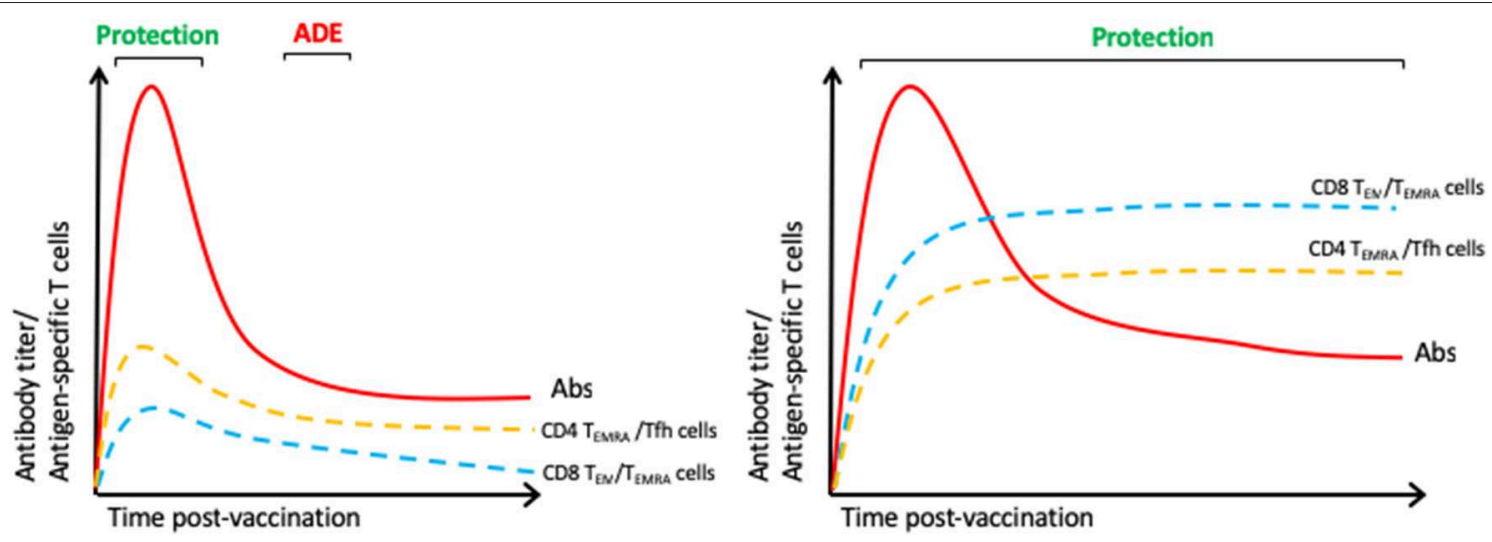

FIGURE 2 | Immune responses of an ideal DENV/ZIKV vaccine. We hypothesize that the licensed DENV vaccine elicits suboptimal antibody responses and inefficient $\mathrm{CD}^{+}$and $\mathrm{CD} 8^{+} \mathrm{T}$ cell responses (Left) and that an ideal vaccine should induce balanced Ab, CD8 ${ }^{+}\left(\mathrm{T}_{\mathrm{EM}} / \mathrm{T}_{\mathrm{EMRA}}\right)$ and $\mathrm{CD} 4^{+}$(Th1, CTL, and Tfh) T cell responses (Right).

vaccine that induces only an $\mathrm{Ab}$ response. In contrast, DENVelicited cross-reactive $\mathrm{CD}^{+} \mathrm{T}$ cells were able to protect against ZIKV in virgin and pregnant mice (37-39). There are direct evidences showing that DENV or ZIKV protein/epitopes induced protection in mice via $\mathrm{T}$ cells. Costa et al. showed that Balb/c mice vaccinated with DNA vaccines based on full-length or helicase domain NS3 of DENV2 are protected against lethal challenge (71). Similarly, we showed protection mediated by $\mathrm{CD}^{+} \mathrm{T}$ cells in AG129 and wild-type mice vaccinated with VRP expressing the DENV2-E protein ectodomain (DENV2 E85-VRP) (72). In this study, $\mathrm{CD} 8^{+} \mathrm{T}$ cells from vaccinated mice significantly contribute to the reduction of viral RNA in tissues (72). Vaccination of human relevant peptides HLArestricted, identified as immunodominant epitopes, contribute to the reduction of DENV/ZIKV viral burden $(37,49)$. We demonstrated that peptide immunization of $\mathrm{HLAB}^{*} 0702$ and HLAA $^{*} 0101$-restricted epitopes contribute to protection. Based on studies implicating an important role for cross-reactive T cells in mediating protection against DENV and ZIKV, a DENV/ZIKV vaccine could be designed to induce balanced $\mathrm{Ab}, \mathrm{CD} 4^{+} \mathrm{Tfh}$, $\mathrm{CD}^{+} \mathrm{Th} 1$, and $\mathrm{CD} 8^{+} \mathrm{T}$ cell responses in order to confer longlived protection that is mediated by both humoral and cellular immunity (Figure 2).

In conclusion, the studies reviewed here strongly support a key role for $\mathrm{T}$ cells in protecting against DENV and

\section{REFERENCES}

1. Murphy BR, Whitehead SS. Immune response to dengue virus and prospects for a vaccine. Annu Rev Immunol. (2011) 29:587-619. doi: 10.1146/annurev-immunol-031210-101315

2. Gubler DJ. Aedes aegypti and Aedes aegypti-borne disease control in the 1990s: top down or bottom up. Charles Franklin Craig Lecture Am J Trop Med Hyg. (1989) 40:571-8. doi: 10.4269/ajtmh.1989.40.571

3. Calisher CH, Karabatsos N, Dalrymple JM, Shope RE, Porterfield JS, Westaway EG, et al. Antigenic relationships between flaviviruses as determined by cross-neutralization tests with polyclonal antisera. J Gen Virol. (1989) 70:37-43. doi: 10.1099/0022-1317-70-1-37
ZIKV infections. Comprehensive studies that examine the $\mathrm{T}$ cell responses in humans at several time points during acute DENV/ZIKV infections and include patients exhibiting a wide spectrum of clinical disease manifestations (including no symptoms), infection history, ethnicity, and geographic location now need to be conducted. Knowledge gained from these studies will provide insights into the design of safe and effective DENV and ZIKV vaccines that elicit balanced $\mathrm{Ab}$ and $\mathrm{T}$ cell responses. Several studies have already shown that DENV/ZIKV proteomes contain cross-reactive immunogenic epitopes that can elicit polyfunctional effector $\mathrm{T}$ cell responses. Thus, we propose that pan-flavivirus vaccine candidates that take into consideration of such epitopes should be designed to solve the global problem associated with genetic and antigenic similarity and co-circulation of DENV and ZIKV.

\section{AUTHOR CONTRIBUTIONS}

AEN wrote the review, and SS edited the review drafts.

\section{ACKNOWLEDGMENTS}

AEN and SS are supported by grants from the National Institutes of Health (AI116813 and AI140063). 
8. Ngono AE, Shresta S. Immune Response to Dengue and Zika. Annu Rev Immunol. (2018) 36:279-308. doi: 10.1146/annurev-immunol-042617053142

9. Salje H, Cummings DAT, Rodriguez-Barraquer I, Katzelnick LC, Lessler J, Klungthong C, et al. Reconstruction of antibody dynamics and infection histories to evaluate dengue risk. Nature. (2018) 557:719-23. doi: 10.1038/s41586-018-0157-4

10. Mongkolsapaya J, Dejnirattisai W, Xu XN, Vasanawathana S, Tangthawornchaikul N, Chairunsri A, et al. Original antigenic sin and apoptosis in the pathogenesis of dengue hemorrhagic fever. Nat Med. (2003) 9:921-7. doi: 10.1038/nm887

11. Rothman AL, Medin CL, Friberg H, Currier JR. Immunopathogenesis versus protection in dengue virus infections. Curr Trop Med Rep. (2014) 1:13-20. doi: 10.1007/s40475-013-0009-0

12. Coudeville L, Baurin N, Vergu E. Estimation of parameters related to vaccine efficacy and dengue transmission from two large phase III studies. Vaccine. (2016) 34:6417-25. doi: 10.1016/j.vaccine.2015.11.023

13. Sridhar S, Luedtke A, Langevin E, Zhu M, Bonaparte M, Machabert T, et al. Effect of dengue serostatus on dengue vaccine safety and efficacy. $N$ Engl J Med. (2018) 379:327-40. doi: 10.1056/NEJMoa1800820

14. Hadinegoro SR, Arredondo-Garcia JL, Capeding MR, Deseda C, Chotpitayasunondh T, Dietze R, et al. Efficacy and long-term safety of a dengue vaccine in regions of endemic disease. $N$ Engl J Med. (2015) 373:1195-206. doi: 10.1056/NEJMoa1506223

15. Guy B, Barrere B, Malinowski C, Saville M, Teyssou R, Lang J. From research to phase III: preclinical, industrial and clinical development of the Sanofi Pasteur tetravalent dengue vaccine. Vaccine. (2011) 29:7229-41. doi: 10.1016/j.vaccine.2011.06.094

16. Guy B, Nougarede N, Begue S, Sanchez V, Souag N, Carre M, et al. Cellmediated immunity induced by chimeric tetravalent dengue vaccine in naive or flavivirus-primed subjects. Vaccine. (2008) 26:5712-21. doi: 10.1016/j.vaccine.2008.08.019

17. Ventura CV, Maia M, Bravo-Filho V, Gois AL, Belfort RJr. Zika virus in Brazil and macular atrophy in a child with microcephaly. Lancet. (2016). 387:228. doi: 10.1016/S0140-6736(16)00006-4

18. Chandele A, Sewatanon J, Gunisetty S, Singla M, Onlamoon N, Akondy RS, et al. Characterization of human CD8 T Cell responses in dengue virus-infected patients from India. J Virol. (2016) 90:11259-78. doi: 10.1128/JVI.01424-16

19. Duangchinda T, Dejnirattisai W, Vasanawathana S, Limpitikul W, Tangthawornchaikul N, Malasit P, et al. Immunodominant T-cell responses to dengue virus NS3 are associated with DHF. Proc Natl Acad Sci USA. (2010) 107:16922-7. doi: 10.1073/pnas.1010867107

20. Rivino L, Tan AT, Chia A, Kumaran EA, Grotenbreg GM, Macary $\mathrm{PA}$, et al. Defining CD8+ $\mathrm{T}$ cell determinants during human viral infection in populations of Asian ethnicity. J Immunol. (2013) 191:4010-9. doi: 10.4049/jimmunol.1301507

21. Weiskopf D, Angelo MA, De Azeredo EL, Sidney J, Greenbaum JA, Fernando AN, et al. Comprehensive analysis of dengue virus-specific responses supports an HLA-linked protective role for CD8+ T cells. Proc Natl Acad Sci USA. (2013) 110:E2046-53. doi: 10.1073/pnas.1305227110

22. Grifoni A, Angelo MA, Lopez B, O’rourke PH, Sidney J, Cerpas C, et al. Global assessment of dengue virus-specific $\mathrm{CD} 4(+) \mathrm{T}$ cell responses in dengueendemic areas. Front Immunol. (2017) 8:1309. doi: 10.3389/fimmu.2017.01309

23. Weiskopf D, Angelo MA, Grifoni A, O'rourke PH, Sidney J, Paul S, et al. HLA-DRB1 alleles are associated with different magnitudes of dengue virus-specific CD4+ T-Cell responses. J Infect Dis. (2016) 214:1117-24. doi: 10.1093/infdis/jiw309

24. Angelo MA, Grifoni A, O'rourke PH, Sidney J, Paul S, Peters B, et al. Human $\mathrm{CD} 4(+) \mathrm{T}$ cell responses to an attenuated tetravalent dengue vaccine parallel those induced by natural infection in magnitude, HLA restriction, and antigen specificity. J Virol. (2017) 91:e02147-16. doi: 10.1128/JVI.02147-16

25. Earl PL, Americo JL, Wyatt LS, Eller LA, Whitbeck JC, Cohen GH, et al. Immunogenicity of a highly attenuated MVA smallpox vaccine and protection against monkeypox. Nature. (2004) 428:182-5. doi: 10.1038/nature02331

26. Zellweger RM, Shresta S. Mouse models to study dengue virus immunology and pathogenesis. Front Immunol. (2014) 5:151. doi: $10.3389 /$ fimmu. 2014.00151
27. Weiskopf D, Yauch LE, Angelo MA, John DV, Greenbaum JA, Sidney J, et al. Insights into HLA-restricted $\mathrm{T}$ cell responses in a novel mouse model of dengue virus infection point toward new implications for vaccine design. $J$ Immunol. (2011) 187:4268-79. doi: 10.4049/jimmunol.1101970

28. Weiskopf D, Angelo MA, Sidney J, Peters B, Shresta S, Sette A. Immunodominance changes as a function of the infecting dengue virus serotype and primary versus secondary infection. J Virol. (2014) 88:11383-94. doi: 10.1128/JVI.01108-14

29. Weiskopf D, Cerpas C, Angelo MA, Bangs DJ, Sidney J, Paul S, et al. Human CD8+ T-cell responses against the 4 dengue virus serotypes are associated with distinct patterns of protein targets. J Infect Dis. (2015) 212:1743-51. doi: 10.1093/infdis/jiv289

30. Rivino L, Kumaran EA, Jovanovic V, Nadua K, Teo EW, Pang SW, et al. Differential targeting of viral components by CD4+ versus CD8+ $\mathrm{T}$ lymphocytes in dengue virus infection. J Virol. (2013) 87:2693-706. doi: 10.1128/JVI.02675-12

31. Green S, Kurane I, Edelman R, Tacket CO, Eckels KH, Vaughn DW, et al. Dengue virus-specific human CD4+ T-lymphocyte responses in a recipient of an experimental live-attenuated dengue virus type 1 vaccine: bulk culture proliferation, clonal analysis, and precursor frequency determination. J Virol. (1993) 67:5962-7.

32. Livingston PG, Kurane I, Dai LC, Okamoto Y, Lai CJ, Men R, et al. Dengue virus-specific, HLA-B35-restricted, human CD8+ cytotoxic T lymphocyte (CTL) clones. Recognition of NS3 amino acids 500 to 508 by CTL clones of two different serotype specificities. J Immunol. (1995) 154:1287-1295.

33. Malavige GN, Rostron T, Rohanachandra LT, Jayaratne SD, Fernando N, De Silva $\mathrm{AD}$, et al. HLA class I and class II associations in dengue viral infections in a Sri Lankan population. PLoS ONE. (2011) 6:e20581. doi: 10.1371/journal.pone.0020581

34. Appanna R, Ponnampalavanar S, Lum Chai See L, Sekaran SD. Susceptible and protective HLA class 1 alleles against dengue fever and dengue hemorrhagic fever patients in a Malaysian population. PLoS ONE. (2010) 5:0013029. doi: 10.1371/journal.pone.0013029

35. Nguyen TP, Kikuchi M, Vu TQ, Do QH, Tran TT, Vo DT, et al. Protective and enhancing HLA alleles, HLA-DRB1*0901 and HLA$A^{*} 24$, for severe forms of dengue virus infection, dengue hemorrhagic fever and dengue shock syndrome. PLoS Negl Trop Dis. (2008) 2:e304. doi: 10.1371/journal.pntd.0000304

36. Grifoni A, Pham J, Sidney J, O'rourke PH, Paul S, Peters B, et al. Prior dengue virus exposure shapes T cell immunity to Zika virus in humans. J Virol. (2017) 91:e01469-17. doi: 10.1128/JVI.01469-17

37. Wen J, Tang WW, Sheets N, Ellison J, Sette A, Kim K, et al. Identification of Zika virus epitopes reveals immunodominant and protective roles for dengue virus cross-reactive CD8+ T cells. Nat Microbiol. (2017) 2:17036. doi: $10.1038 / \mathrm{nmicrobiol} .2017 .36$

38. Wen J, Elong Ngono A, Regla-Nava JA, Kim K, Gorman MJ, Diamond MS, et al. Dengue virus-reactive CD8(+) T cells mediate cross-protection against subsequent Zika virus challenge. Nat Commun. (2017) 8:1459. doi: 10.1038/s41467-017-01669-z

39. Regla-Nava JA, Elong Ngono A, Viramontes KM, Huynh AT, Wang YT, Nguyen AT, et al. Cross-reactive Dengue virus-specific CD8(+) T cells protect against Zika virus during pregnancy. Nat Commun. (2018) 9:3042. doi: 10.1038/s41467-018-05458-0

40. Herrera BB, Tsai WY, Chang CA, Hamel DJ, Wang WK, Lu Y, et al. Sustained specific and cross-reactive T cell responses to zika and dengue virus NS3 in West Africa. J Virol. (2018) 92:e01992-17. doi: 10.1128/JVI.01992-17

41. Lim MQ, Kumaran EAP, Tan HC, Lye DC, Leo YS, Ooi EE, et al. Cross-reactivity and anti-viral function of dengue capsid and NS3specific memory T cells toward zika virus. Front Immunol. (2018) 9:2225. doi: 10.3389/fimmu.2018.02225

42. Green S, Pichyangkul S, Vaughn DW, Kalayanarooj S, Nimmannitya S, Nisalak A, et al. Early CD69 expression on peripheral blood lymphocytes from children with dengue hemorrhagic fever. J Infect Dis. (1999) 180:1429-35. doi: 10.1086/315072

43. Mangada MM, Endy TP, Nisalak A, Chunsuttiwat S, Vaughn DW, Libraty DH, et al. Dengue-specific T cell responses in peripheral blood mononuclear cells obtained prior to secondary dengue virus infections in Thai schoolchildren. $J$ Infect Dis . (2002) 185:1697-703. doi: 10.1086/340822 
44. Talarico LB, Batalle JP, Byrne AB, Brahamian JM, Ferretti A, Garcia AG, et al. The role of heterotypic DENV-specific CD8(+)T Lymphocytes in an immunocompetent mouse model of secondary dengue virus infection. EBioMedicine. (2017) 20:202-16. doi: 10.1016/j.ebiom.2017.04.033

45. Simon-Loriere E, Duong V, Tawfik A, Ung S, Ly S, Casademont I, et al. Increased adaptive immune responses and proper feedback regulation protect against clinical dengue. Sci Transl Med. (2017) 9:5088. doi: $10.1126 /$ scitranslmed.aal5088

46. Wijeratne DT, Fernando S, Gomes L, Jeewandara C, Ginneliya A, Samarasekara S, et al. Quantification of dengue virus specific $\mathrm{T}$ cell responses and correlation with viral load and clinical disease severity in acute dengue infection. PLoS Negl Trop Dis. (2018) 12:e0006540. doi: 10.1371/journal.pntd.0006540

47. Zompi S, Santich BH, Beatty PR, Harris E. Protection from secondary dengue virus infection in a mouse model reveals the role of serotype cross-reactive B and T cells. J Immunol. (2012) 188:404-16. doi: 10.4049/jimmunol.1102124

48. Zellweger RM, Tang WW, Eddy WE, King K, Sanchez MC, Shresta S. CD8+ $\mathrm{T}$ cells can mediate short-term protection against heterotypic dengue virus reinfection in mice. J Virol. (2015) 89:6494-505. doi: 10.1128/JVI.00036-15

49. Elong Ngono A, Chen HW, Tang WW, Joo Y, King K, Weiskopf D, et al. Protective role of cross-reactive CD8 T cells against dengue virus infection. EBioMedicine. (2016) 13:284-93. doi: 10.1016/j.ebiom.2016.10.006

50. Weiskopf D, Angelo MA, Bangs DJ, Sidney J, Paul S, Peters B, et al. The human $\mathrm{CD} 8+\mathrm{T}$ cell responses induced by a live attenuated tetravalent dengue vaccine are directed against highly conserved epitopes. J Virol. (2015) 89:120-8. doi: 10.1128/JVI.02129-14

51. De Alwis R, Bangs DJ, Angelo MA, Cerpas C, Fernando A, Sidney J, et al. Immunodominant dengue virus-specific $\mathrm{CD} 8+\mathrm{T}$ cell responses are associated with a memory PD-1+ phenotype. J Virol. (2016) 90:4771-9. doi: 10.1128/JVI.02892-15

52. Rivino L, Kumaran EA, Thein TL, Too CT, Gan VC, Hanson BJ, et al. Virusspecific T lymphocytes home to the skin during natural dengue infection. Sci Transl Med. (2015) 7:278ra35. doi: 10.1126/scitranslmed.aaa0526

53. Weiskopf D, Bangs DJ, Sidney J, Kolla RV, De Silva AD, De Silva AM, et al. Dengue virus infection elicits highly polarized CX3CR1+ cytotoxic CD4+ T cells associated with protective immunity. Proc Natl Acad Sci USA. (2015) 112:E4256-63. doi: 10.1073/pnas.1505956112

54. Patil VS, Madrigal A, Schmiedel BJ, Clarke J, O'rourke P, De Silva AD, et al. Precursors of human $\mathrm{CD} 4(+)$ cytotoxic T lymphocytes identified by single-cell transcriptome analysis. Sci Immunol. (2018) 3:aan8664. doi: 10.1126/sciimmunol.aan8664

55. Haltaufderhyde K, Srikiatkhachorn A, Green S, Macareo L, Park S, Kalayanarooj S, et al. Activation of peripheral $\mathrm{T}$ follicular helper cells during acute dengue virus infection. J Infect Dis. (2018) 218:1675-85. doi: $10.1093 /$ infdis/jiy360

56. Paquin-Proulx D, Leal FE, Terrassani Silveira CG, Maestri A, Brockmeyer C, Kitchen SM, et al. T-cell Responses in Individuals Infected with Zika Virus and in Those Vaccinated Against Dengue Virus. Pathog Immun. (2017) 2:274-92. doi: 10.20411/pai.v2i2.188

57. Huang H, Li S, Zhang Y, Han X, Jia B, Liu H, et al. CD8+ T cell immune response in immunocompetent mice during zika virus infection. $J$ Virol. (2017) 91:e00900-17. doi: 10.1128/JVI.00900-17

58. Muyanja E, Ssemaganda A, Ngauv P, Cubas R, Perrin H, Srinivasan D, et al. Immune activation alters cellular and humoral responses to yellow fever 17D vaccine. J Clin Invest. (2014) 124:3147-58. doi: 10.1172/JCI75429

59. Akondy RS, Monson ND, Miller JD, Edupuganti S, Teuwen D, Wu H, et al. The yellow fever virus vaccine induces a broad and polyfunctional human memory CD8+ T cell response. J Immunol. (2009) 183:7919-30. doi: 10.4049/jimmunol.0803903
60. Sabchareon A, Wallace D, Sirivichayakul C, Limkittikul K, Chanthavanich $\mathrm{P}$, Suvannadabba S, et al. Protective efficacy of the recombinant, liveattenuated, CYD tetravalent dengue vaccine in Thai schoolchildren: a randomised, controlled phase $2 \mathrm{~b}$ trial. Lancet. (2012) 380:1559-67. doi: 10.1016/S0140-6736(12)61428-7

61. Guy B, Jackson N. Dengue vaccine: hypotheses to understand CYD-TDV-induced protection. Nat Rev Microbiol. (2016) 14:45-54. doi: 10.1038/nrmicro.2015.2

62. Harenberg A, Begue S, Mamessier A, Gimenez-Fourage S, Ching Seah C, Wei Liang A, et al. Persistence of Th1/Tc1 responses one year after tetravalent dengue vaccination in adults and adolescents in Singapore. Hum Vaccin Immunother. (2013) 9:2317-25. doi: 10.4161/hv.25562

63. Durbin AP, Kirkpatrick BD, Pierce KK, Elwood D, Larsson CJ, Lindow JC, et al. A single dose of any of four different live attenuated tetravalent dengue vaccines is safe and immunogenic in flavivirus-naive adults: a randomized, double-blind clinical trial. J Infect Dis. (2013) 207:957-65. doi: 10.1093/infdis/jis936

64. Chu H, George SL, Stinchcomb DT, Osorio JE, Partidos CD. CD8+ Tcell responses in flavivirus-naive individuals following immunization with a live-attenuated tetravalent dengue vaccine candidate. J Infect Dis. (2015) 212:1618-28. doi: 10.1093/infdis/jiv258

65. Fernandez E, Diamond MS. Vaccination strategies against Zika virus. Curr Opin Virol. (2017) 23:59-67. doi: 10.1016/j.coviro.2017.03.006

66. Larocca RA, Abbink P, Peron JP, Zanotto PM, Iampietro MJ, Badamchi-Zadeh A, et al. Vaccine protection against Zika virus from Brazil. Nature. (2016) 536:474-8. doi: 10.1038/nature18952

67. Abbink P, Larocca RA, Visitsunthorn K, Boyd M, De La Barrera RA, Gromowski GD, et al. Durability and correlates of vaccine protection against Zika virus in rhesus monkeys. Sci Transl Med. (2017) 9:aao4163. doi: 10.1126/scitranslmed.aao4163

68. George J, Valiant WG, Mattapallil MJ, Walker M, Huang YS, Vanlandingham $\mathrm{DL}$, et al. Prior exposure to zika virus significantly enhances peak dengue-2 viremia in rhesus macaques. Sci Rep. (2017) 7:10498. doi: 10.1038/s41598-017-10901-1

69. Fowler AM, Tang WW, Young MP, Mamidi A, Viramontes KM, Mccauley MD, et al. Maternally acquired zika antibodies enhance dengue disease severity in mice. Cell Host Microbe. (2018) 24:743-50 e5. doi: 10.1016/j.chom.2018.09.015

70. Stettler K, Beltramello M, Espinosa DA, Graham V, Cassotta A, Bianchi S, et al. Specificity, cross-reactivity, and function of antibodies elicited by Zika virus infection. Science. (2016) 353:823-6. doi: 10.1126/science.aaf8505

71. Costa SM, Yorio AP, Goncalves AJ, Vidale MM, Costa EC, MohanaBorges $\mathrm{R}$, et al. Induction of a protective response in mice by the dengue virus NS3 protein using DNA vaccines. PLoS ONE. (2011) 6:e25685. doi: 10.1371/journal.pone. 0025685

72. Zellweger RM, Miller R, Eddy WE, White LJ, Johnston RE, Shresta S. Role of humoral versus cellular responses induced by a protective dengue vaccine candidate. PLoS Pathog. (2013) 9:e1003723. doi: 10.1371/journal.ppat.1003723

Conflict of Interest Statement: The authors declare that the research was conducted in the absence of any commercial or financial relationships that could be construed as a potential conflict of interest.

Copyright $\odot 2019$ Elong Ngono and Shresta. This is an open-access article distributed under the terms of the Creative Commons Attribution License (CC BY). The use, distribution or reproduction in other forums is permitted, provided the original author(s) and the copyright owner(s) are credited and that the original publication in this journal is cited, in accordance with accepted academic practice. No use, distribution or reproduction is permitted which does not comply with these terms. 